\title{
Bulge tests on ferroelastic and superelastic NiTi sheets with full field thermal and 3D-kinematical measurements: experiments and modelling
}

\author{
V. Grolleau ${ }^{1}$, H. Louche ${ }^{2,4}$, A. Penin ${ }^{1}$, P. Chauvelon ${ }^{1}$, G. Rio ${ }^{1}$, Y. Liu $^{3}$, D. Favier ${ }^{4 a}$ \\ ${ }^{1}$ Université Européenne de Bretagne, LIMATB, Rue de Saint Maudé - BP 92116, 56321 Lorient cedex, France \\ ${ }^{2}$ Université de Savoie, SYMME, BP 80439, 74944 Annecy le Vieux cedex, France \\ ${ }^{3}$ The University of Western Australia. School of Mechanical Engineering, Crawley, WA 6009, Australia \\ ${ }^{4}$ Université de Grenoble/CNRS, 3S-R, BP 53, 38041 Grenoble Cedex 09, France
}

\begin{abstract}
Superelastic and ferroelastic behaviour of polycrystalline Nickel-Titanium Shape Memory Alloys have been extensively studied, mostly via uniaxial tension and compression, simple shear and more recently in combination of tension (compression)-torsion tests. This paper reports on a study of tensile tests and thin plate bulging tests of NiTi. The bulging tests were performed on a circular diaphragm in both superelastic and ferroelastic states at room temperature. Thermal and 3D kinematical full-field measurements were simultaneously conducted owing to the use of one Infrared camera and two visible cameras. The bulging loading creates plane tensile deformation state along the rim of the circular bulge specimen and equi-biaxial deformation state at the centre. In this region, measurements of the curvature radius and of the bulging pressure allow to determine the equi-biaxial stress values. Occurrences of deformation localisation during tensile and bulge tests are studied as function of the deformation mechanisms and of the type of loading. Experimental results are compared with simulated results obtained using "Herezh" Finite Element software in which an "elastohysteresis" constitutive equation is implemented. The parameters of the law are determined from tensile tests on the two sheets and analysis of the equibiaxial deformation behaviour in the region close to the centre of the bulge specimens.
\end{abstract}

\section{Introduction}

As engineering components utilising the beneficial properties of shape memory alloys (SMA) become geometrically complex and as applications involve combinations of loading states, a full evaluation of the effects of stress state on stress strain response of these materials becomes critical for the success of these applications. Such evaluation is required to establish reliable constitutive relationship to model the complex thermomechanical behaviour of SMAs.

This paper reports on a study of the behaviour of NiTi sheets under biaxial loading conditions, in contrast to previous studies in tension, compression and shear tests [1-6].

\section{Experimental set-up}

\subsection{Materials}

Two commercial NiTi alloys were used, including Ti-50.2 at \% Ni plates (alloy A, thickness $0.36 \mathrm{~mm}$ ) and Ti-50.8 at $\% \mathrm{Ni}$ plates (alloy B, thickness $0.11 \mathrm{~mm}$ ). Transformation behaviour of the two alloys, as measured by means of differential scanning calorimetry (DSC), is shown in figure 1. For mechanical testing, alloy A was cooled in liquid nitrogen prior to the tests so that it was in martensitic state at room temperature. Alloy B was heated to $100^{\circ} \mathrm{C}$ prior to the tests so that it was in austenitic state at room temperature.

\subsection{Tension tests}

Tension tests were performed at room temperature $\mathrm{T}_{0}=288 \mathrm{~K}$, at a constant cross head velocity $=310^{-3} \mathrm{~mm} / \mathrm{s}$, on rectangular specimens of 50x5 mm in size for the two alloy sheets, with a gauge length of $30 \mathrm{~mm}$. The tests were performed using an Instron 5569 conventional tensile testing machine at a mean strain rate of $10^{-4} \mathrm{~s}^{-1}$. Temperature, displacement and strain field were recorded during these tests [6-8]. Figure 2 presents nominal stress-strain curves (in dashed lines) of the samples.

\footnotetext{
a e-mail: denis.favieregrenoble-inp.fr
}

This is an Open Access article distributed under the terms of the Creative Commons Attribution-Noncommercial License (http://creativecommons.org/licenses/by-nc/3.0/), which permits unrestricted use, distribution, and reproduction in any noncommercial medium, provided the original work is properly cited. 
The specimen cross-section and the relative displacement of the two extremities of the specimen gauge length are determined from the displacement field. Thermal and kinematical fields revealed strong localisation effects for the two alloys, implying Lüders-like deformation behaviour [9,10] for both the ferroleastic and superelastic behaviour. Tensile tests were performed on superelastic specimens cut in the rolling and transverse directions. As seen in (b), the alloy sheet exhibits some anisotropy effect.

a)

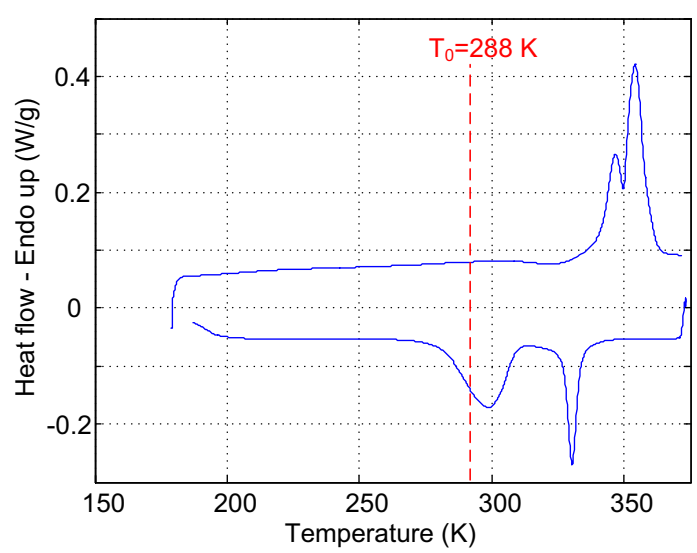

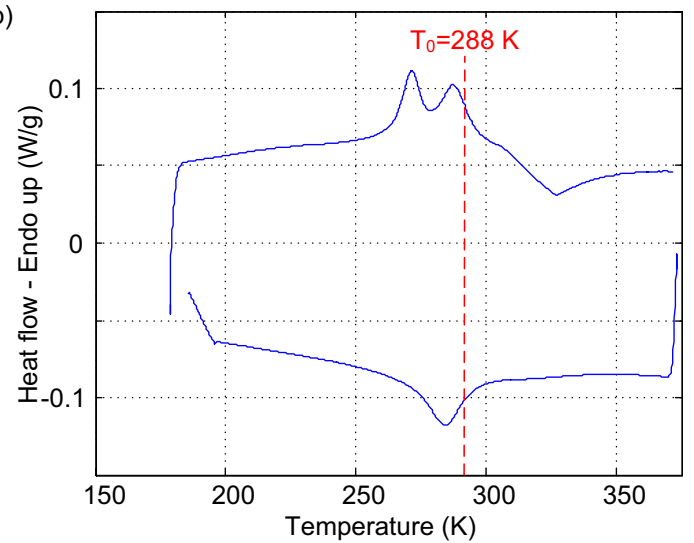

Fig. 1. Transformation behaviours of a) Alloy A and b) Alloy B

a)

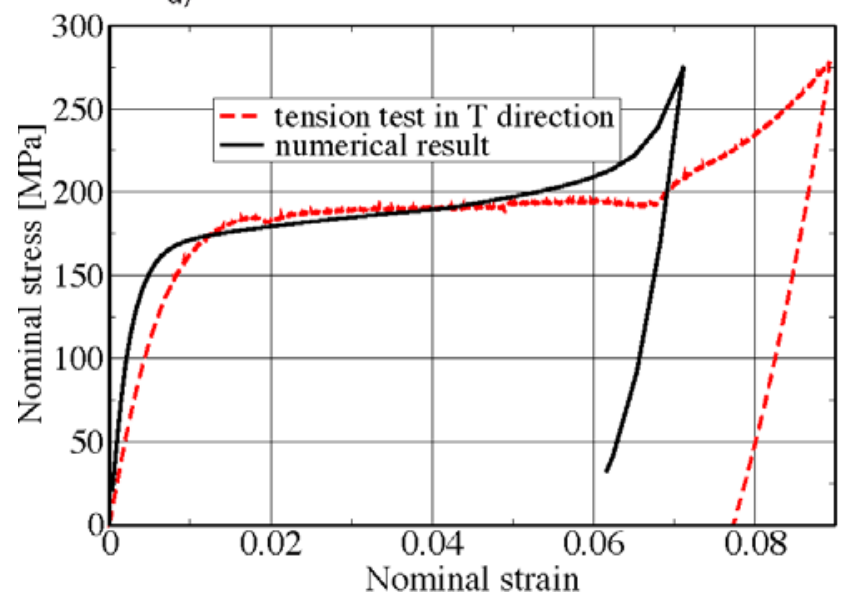

b)

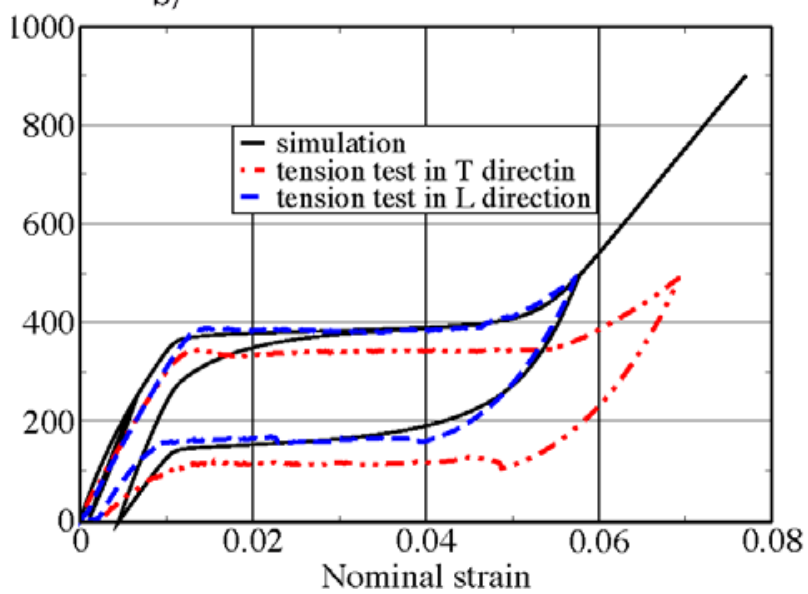

Fig. 2. Tensile tests at room temperature $\left(T_{0}=293 \mathrm{~K}\right)$ - Experiments in dashed lines- Simulations in continuous lines- a) Alloy A (ferroelastic) b) Alloy B (superelastic) for specimens cut along (L) or perpendicular (T) to the rolling direction.

\subsection{Bulge test}

\subsubsection{Experimental set-up}

Bulge tests were carried out on square blanks of $80 \times 80 \mathrm{~mm}$ in dimension, by forming a $60 \mathrm{~mm}$ diameter bulge as shown in figure 3a. The blanks were locked with a blank-holder and a draw-bead. The chamber between the blank and the punch was filled with water. A cylindrical punch of $60 \mathrm{~mm}$ in diameter moves upwards at a constant velocity of $0.2 \mathrm{~mm} / \mathrm{s}$ [11,12] to apply the pressure for the bulging.

\subsubsection{Full field measurements}

During the tests, pressure, temperature and displacement fields were recorded using the two visible cameras and the infrared camera, as shown in figure $3 \mathrm{~b}$. A random texture created by using white spray on a uniform black paint was coated on the NiTi plates to facilitate digital image correlation (DIC) and thermal measurements. Compatibility of such a texture for simultaneous infrared and visible observations was tested in [6]. An emissivity close to 0.95 is then expected. The infrared camera (CEDIP Jade MW III) has a resolution of 320x240 pixels and a thermal resolution of NETD=20 mK. Thermal images were recorded at a frequency of $10 \mathrm{~Hz}$. 

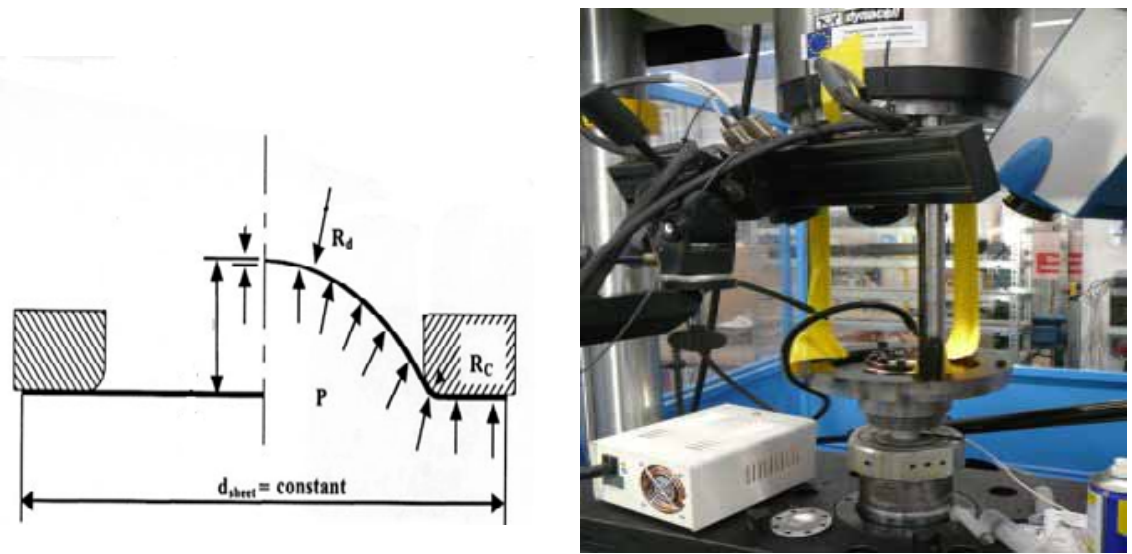

Fig. 3. Bulge test principle and experimental set-up with two visible cameras and one IR camera

\section{Bulge tests- Results}

\subsection{Pressure-displacement}

The experimental pressure-apex displacement curves are presented in figures 4 , in red dashed lines. 

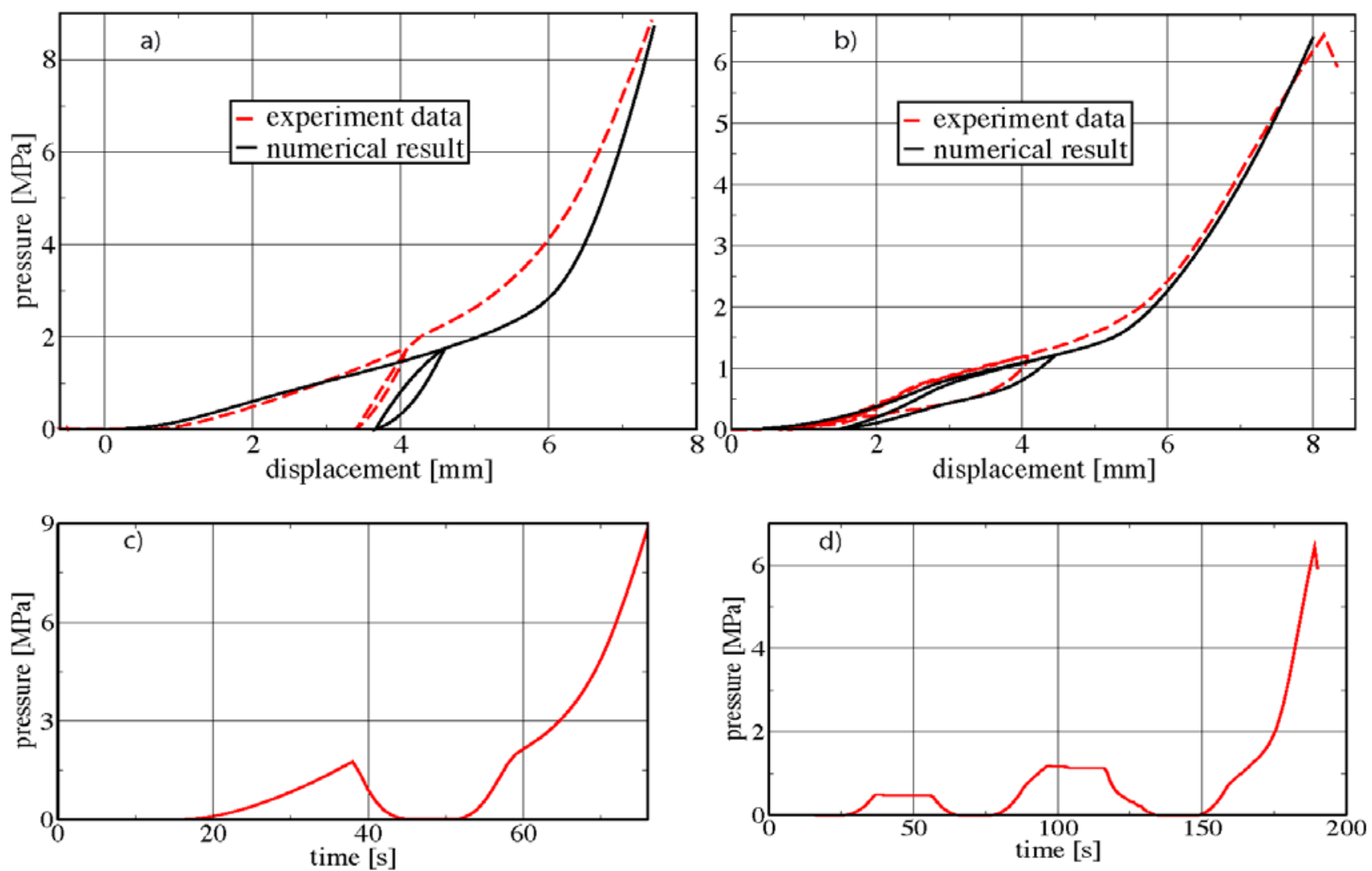

Fig. 4. Bulge test at room temperature. Pressure-Apex displacement for the two alloys. Experimental curves are expressed in dashed red lines. Finite Element Simulation curves are shown in continuous black lines: a) Alloy A. ferroelastic, b) Alloy B superelastic, c) and d) time-evolutions of pressure corresponding respectively to a) and b).

\subsection{Temperature and strain fields}

Temperature measurements are presented in figures 5 and 6 for the two alloys. Figure 5a shows the temperature variation field $\theta=\mathrm{T}-\mathrm{T}_{0}$ at $\mathrm{t}_{3}=38 \mathrm{~s}$ for alloy A and figure $6 \mathrm{a}$ shows the temperature variation field at $\mathrm{t}_{5}=95 \mathrm{~s}$ for Alloy $\mathrm{B}$. Temperature variations at the apex points of the two alloys are plotted over time in figures $5 \mathrm{~b}$ and $6 \mathrm{~b}$, respectively. In order to compare these evolutions, specific times have been selected in these figures. For Alloy A (Figure $5 b$ ) the first loading starts at time $t_{1}$ and finishes at time $t_{3}$ where the plate was unloaded. Then a second loading starts at time $t_{4}$ until failure at around time 80s. Temperature variations are correlated with these steps. It is noticeable that a weak decrease (about $-0.2 \mathrm{~K}$ ) is observed at the beginning of each loading (between $\left[\mathrm{t}_{1}, \mathrm{t}_{2}\right]$ and $\left[\mathrm{t}_{4}, \mathrm{t}_{5}\right]$ ). Then, positive temperature variations (about $1.5 \mathrm{~K}$ ) were measured during the second loading part. Temperature history in the apex zone is very different for Alloy B (Figure 6b). Intensities are more pronounced (about $-2.5 \mathrm{~K}$ to $+3.5 \mathrm{~K}$ ) and no temperature decrease was observed at the beginning of loading. Positive and negative temperature variations appeared, respectively, during the three successive loadings and the two unloadings. In the last test (Alloy B, Fig. $6 \mathrm{~b}$ ) the loading was stopped after the first $\left(\left[\mathrm{t}_{2}, \mathrm{t}_{3}\right]\right)$ and second loading $\left(\left[\mathrm{t}_{5}, \mathrm{t}_{6}\right]\right)$ in order to compare the natural temperature decrease and the one measured during unloading. One can note that temperature variations during unloading (just after $t_{3}$ and $t_{6}$ ) were faster than during natural cooling (plateaus $\left[t_{2}, t_{3}\right]$ and $\left[t_{5}, t_{6}\right]$ ). 

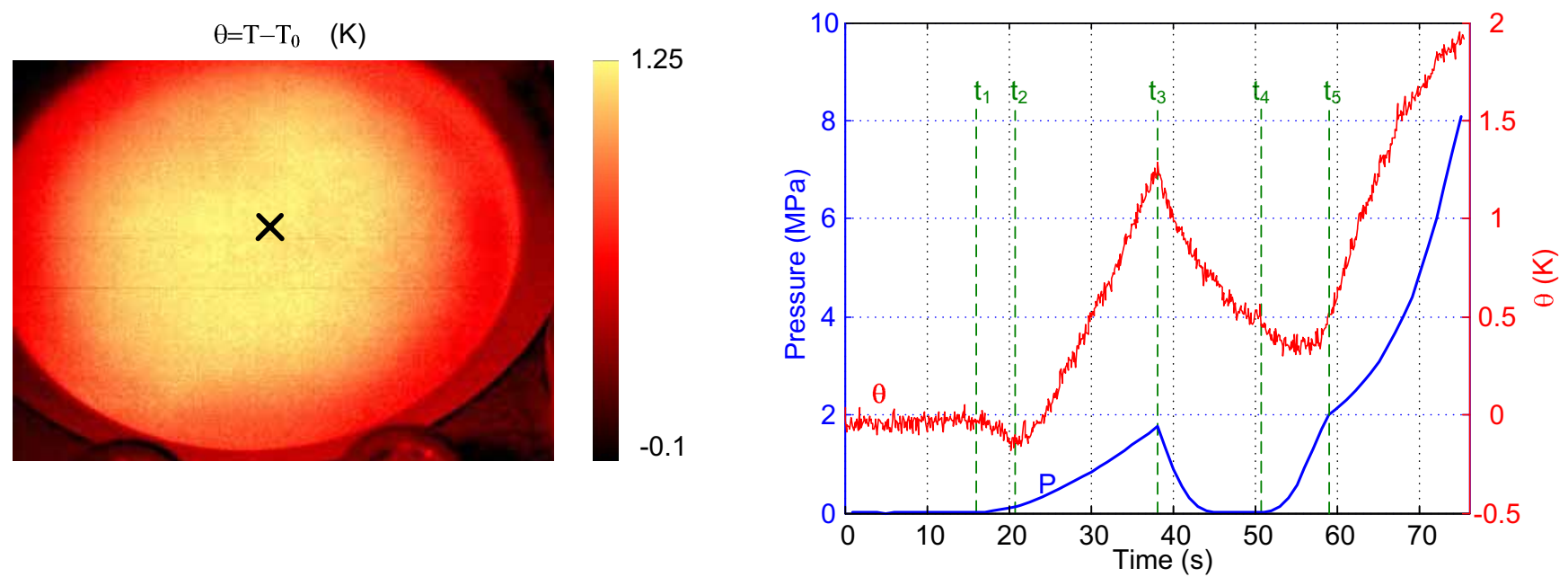

Fig. 5. Bulge test at room temperature $\left(T_{0}=288 \mathrm{~K}\right)$ of alloy A. a) Temperature field at time $t_{3}$; b) Temperature as function of time at the apex point shown in Fig. 5a.

$\theta=\mathrm{T}-\mathrm{T}_{0} \quad(\mathrm{~K})$

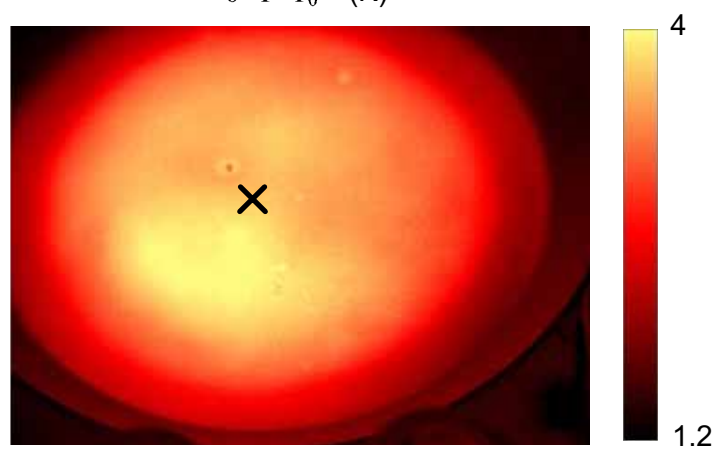

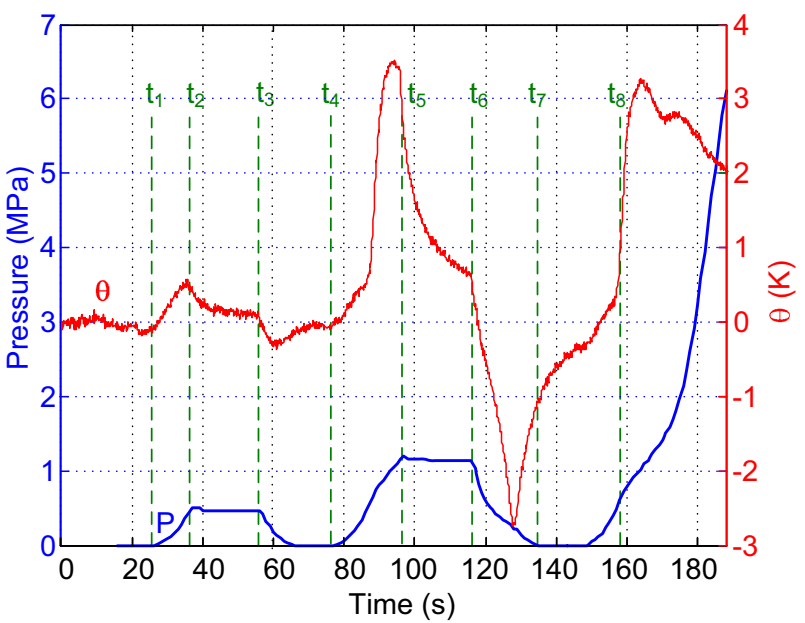

Fig. 6. Bulge test at room temperature $\left(T_{0}=288 \mathrm{~K}\right)$ of alloy B. a) Temperature field at time $t_{5} ;$ b) Temperature as function of time at the apex point shown in Fig. 6a.

\subsection{Strain fields}

Figure 7 presents the Mises strain map at time $33 \mathrm{~s}$ and the Mises strain histories of four points for alloy A. Figure 8 presents the Mises strain map at time $30 \mathrm{~s}$ and the Mises strain histories of four points for alloy B. 
a)

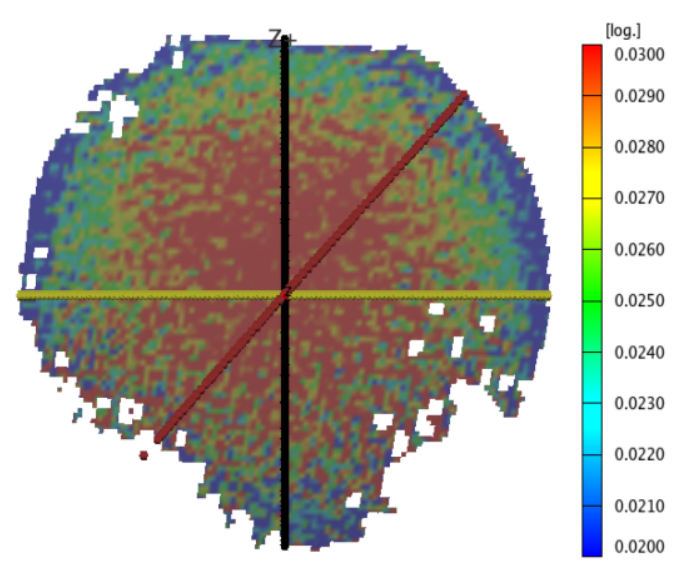

b)

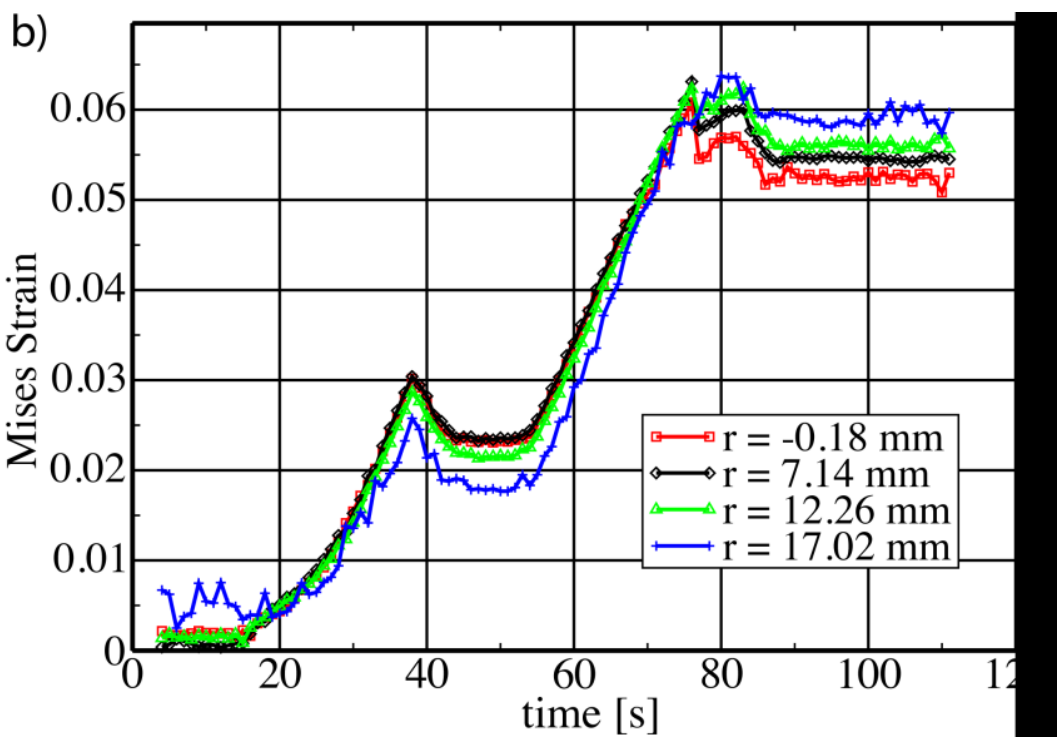

Fig. 7. Bulge test of alloy A at room temperature $\left(T_{0}=288 \mathrm{~K}\right)$ : a) Mises strain field at time $37 \mathrm{~s}$; b) Time histories of Mises strains at 4 points located from the apex center.
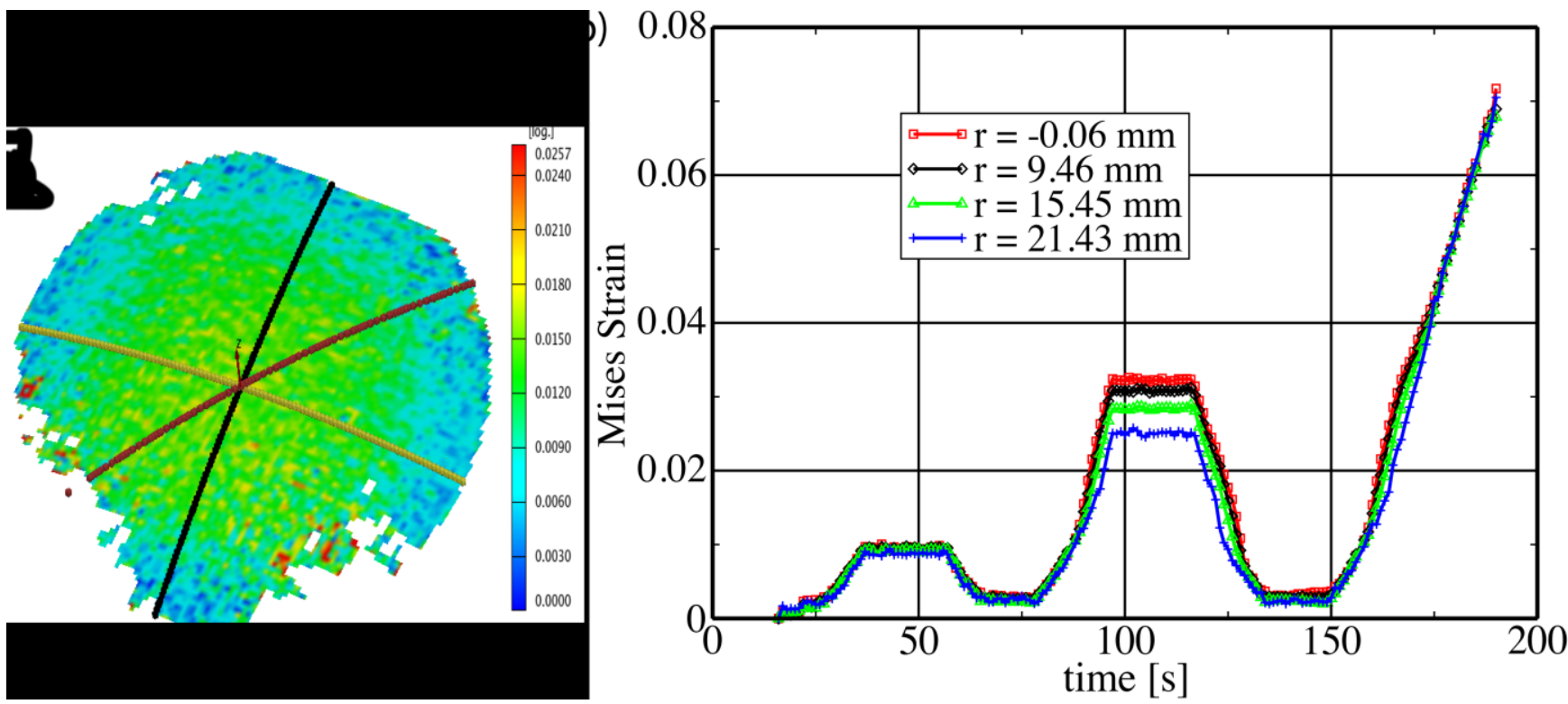

Fig. 8. Bulge test of alloy B at room temperature $\left(T_{0}=288 \mathrm{~K}\right)$ : a) Mises strain field at time $30 \mathrm{~s}$; Time histories of Mises strains at 4 points located from the apex center.

\section{Modelling}

\subsection{Constitutive equations}

As proposed in $[13,14]$, the permanence of the simultaneous existence of reversible processes and hysteresis in the thermomechanical behaviour of shape memory alloys suggests to express the total stress $\sigma$ as the addition of two partial stresses, the first $\sigma_{\mathrm{r}}$ being hyperelastic while the second one is related to hysteresis of elastoplastic type [15,16]. A 1-D illustration of the "elastohysteresis model" is shown in figure 9a.

In the present work, the partial hyperelastic stress tensor is calculated from the hyperelastic potential proposed by Orgéas $[3,17]$, which leads to the 1-D case (shear test) to the stress-strain curve shown in figure 10a. The potential $\omega=\omega\left(V, Q_{\varepsilon}, \varphi_{\varepsilon}\right)$ is expressed as function of 3 invariants of the Almansi strain tensor: the relative variation of volume $V$, the intensity of the deviatoric deformation $Q_{\varepsilon}$, and $\varphi_{\varepsilon}$ a measure of the angle giving the direction of the deformation tensor in the deviatoric plane. $\varphi_{\varepsilon}$ is used to model the non-symmetric tension-compression behaviour, as shown in figure 9b [1-4]. The hyperelastic model depends on 8 parameters. K controls the compressibility. The significance of the 7 remaining 
parameters is shown in figure 10a.

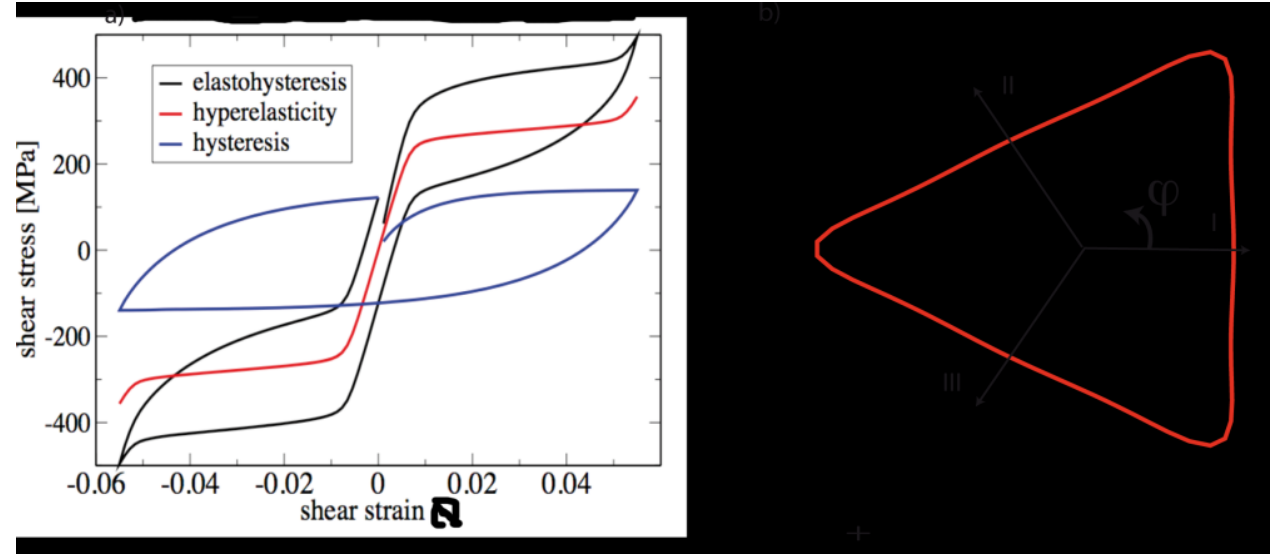

Fig. 9. a) Elastohysteresis model (black line) with the hyperelastic (red line) and hysteresis (blue line) partial stresses; b) function $f(\varphi)$ used to describe the tension-compression asymmetry, where $\varphi$ is the phase of the deviatoric deformation.

Therefore, only one test is required to identify these 7 parameters. Parameters $Q_{s}, \mu_{1}$ and $\mu_{2}$ are functions of $\varphi_{\varepsilon}$, with:

$$
\begin{aligned}
& \mathbf{Q}_{\mathbf{s}}(\varphi)=\mathbf{Q}_{\mathbf{s}} \mathbf{f}(\varphi) ; \mu_{1}(\varphi)=\mu_{\mathbf{1}} \mathbf{f}(\varphi) ; \mu_{\mathbf{2}}(\varphi)=\mu_{\mathbf{2}} \mathbf{f}(\varphi) \\
& \text { with } \mathbf{f}(\varphi)=\frac{1 .}{(\mathbf{1}+\gamma \cos 3 \varphi)^{\mathbf{n}}} ; \gamma=\mathbf{0 . 9} \text { and } \mathbf{n}=\mathbf{0 . 2}
\end{aligned}
$$

Parameter $Q_{\varepsilon}$ is also taken as a function of $\varphi_{\varepsilon}$. In order to express the independence of the transformation energy on loading type [3], this function has been chosen so that the product $\mathrm{Q}_{s}(\varphi) \mathrm{Q}_{\varepsilon}(\varphi)$ is independent of $\varphi$.

The hysteresis is described by an incremental model of hypoelastic type :

$$
\dot{\boldsymbol{\sigma}}=2 \mu \overline{\boldsymbol{D}}+\beta \Phi \Delta_{R}^{t} \overline{\boldsymbol{\sigma}}
$$

and an algorithm to manage discrete memory points introduced by P.Guélin [15] and used in the model. More details can be found in [13-19]. Figure $10 \mathrm{~b}$ shows the meaning of the 2 parameters used in this work.
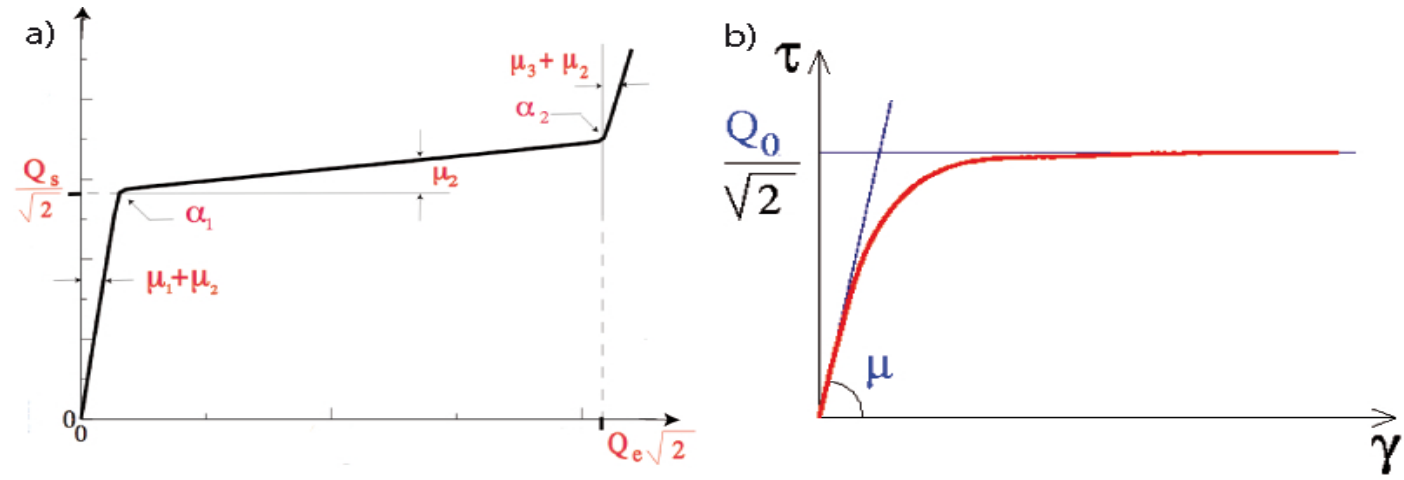

Fig 10. 1D illustration of the signification of constitutive equations parameters a) hyperelasticity, b) hysteresis

Parameters identification: The $\mathrm{K}$ modulus is taken in the literature. The 7 remaining hyperelastic parameters and the two related to hysteresis are identified for B alloy from tensile test (cf. figure $2 b$ ). The chosen coefficients $(n, \gamma)$ produce a ratio of approximately 2 between tension and compression [3]. For alloy A, only two parameters are adapted: Qs, which represents the level of the plateau, and $Q_{\varepsilon}$, which represents the length of the plateau. They are identified in figure 2a. 
Table 1. Parameters for alloys A and B.

\begin{tabular}{|l|l|l|l|l|l|l|l|l|l|l|l|l|l|l|}
\hline \multicolumn{9}{|c|}{ Hyperelasticity } & \multicolumn{4}{c|}{ Hysteresis } \\
\hline Parameters & $\mathrm{K}(\mathrm{GPa})$ & $\mathrm{Qs}(\mathrm{MPa})$ & $\mu 1(\mathrm{GPa})$ & $\mu 2(\mathrm{GPa})$ & $\mu 3(\mathrm{GPa})$ & $\alpha 1$ & $\alpha 2$ & $\mathrm{Q} \varepsilon$ & $\gamma$ & $\mathrm{n}$ & $\mathrm{Q} 0(\mathrm{MPa})$ & $\mu(\mathrm{GPa})$ & $\mathrm{Np}$ \\
\hline Alloy A & 270 & 40 & 9.5 & 0.4 & 10 & 0.001 & 0.005 & 0.065 & 0.9 & 0.2 & 95 & 10.5 & 2 \\
\hline Alloy B & 270 & 245 & 9.5 & 0.4 & 10 & 0.001 & 0.005 & 0.05 & 0.9 & 0.2 & 95 & 10.5 & 2 \\
\hline
\end{tabular}

\subsection{Finite element simulations}

We use full quadratic quadrangular axisymmetric elements and 9 gauss points for quadrature. The meshes include $16 \mathrm{x} 2$ elements for a section of 30x0.36 mm for alloy A and 30x0.11 mm for alloy B in the bulge test. The calculus is controlled by the pressure. The blank is clamped for Y-max (in axisymmetric space). Note that the use of 2 elements in the thickness allows to capture precisely the flexion behaviour.

The simulated pressure-apex evolutions for the two alloys, as shown in figures $4 \mathrm{a}$ and $4 \mathrm{~b}$, are similar to the experimental data, in particular for the loops which shapes are very different for the two alloys. In order to use the simulation, Figure 11 presents 3 simulated sections of the deformed mesh. The comparison of curves A and B highlights the capability of strain recovery for alloy B (3\% in this case). In the case of alloy A $(0.36 \mathrm{~mm}$ thick), we observe a small gradient in the thickness (bending effect). For alloy B $(0.11 \mathrm{~mm}$ thick), this effect is negligible.

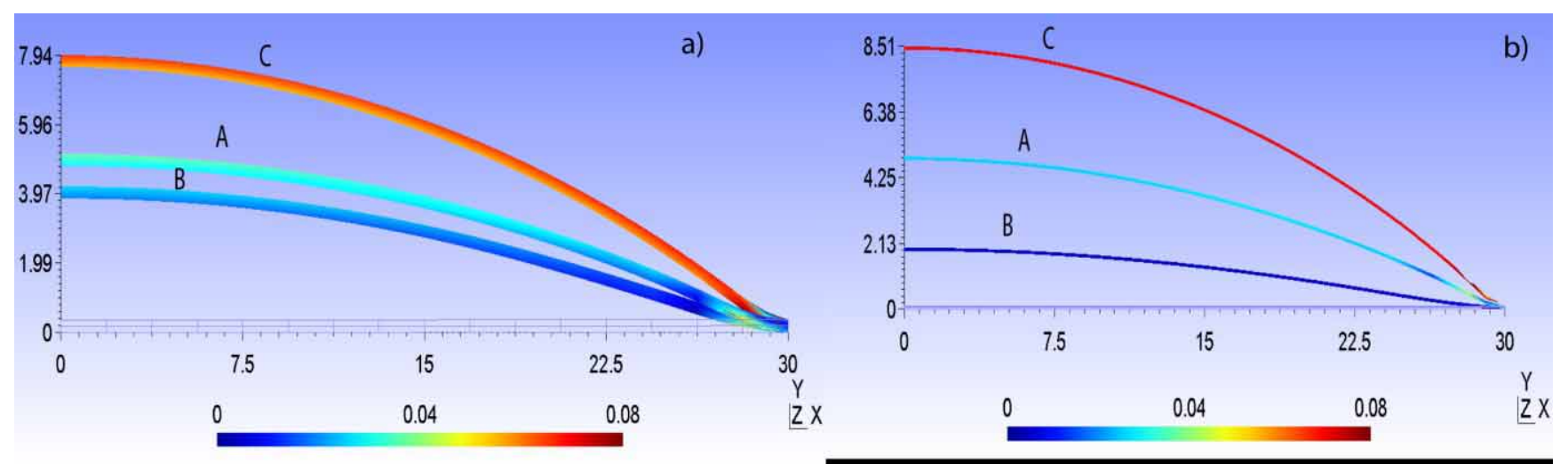

Fig. 11. Strain isovalues on half of the deformed mesh at 3 pressure levels (cf. figure 4): curve A: beginning of the last unload loop, curve $\mathrm{B}$ : end of the last unload loop, curve C: maximum loading. a) alloy A, b) alloy B. The distance in the $\mathrm{x}, \mathrm{y}$ directions are expressed in mm.

\section{Conclusions}

This paper presents first experimental and modelling work on NiTi bulge tests for superelastic and ferroelastic NiTi alloys. The experimental tests are compared to numerical results obtained using the elastohysteresis model. All the trends are respected globally, and we have found the right evolutions. Simultaneous thermal and 3D kinematical full-field measurements were conducted, and first results are presented. The next step will be to compare in detail these numerical and experimental fields, in particular in relation to the stress-induced martensitic transformation in these alloys.

\section{Acknowledgements}

We would like to thank French and Australian ministries for their support through the Program France-Australia Partenariat Hubert Curien 2008-2010 and FR080008 "Lüders-like deformation behaviour of near-equiatomic NiTi shape memory alloys".

\section{References}

[1] P.Y. Manach, PhD thesis, Université de Grenoble, France, 1993.

[2] P.Y. Manach, and D. Favier, Materials Science and Engineering A, vol. 222, 45-57, 1997.

[3] L. Orgéas, PhD thesis, Université de Grenoble, France, 1997. 
[4] L. Orgéas and D. Favier, Acta Materialia, vol. 46, 5579-5591, 1998.

[5] L. Orgéas, Y. Liu, and D. Favier, J. Phys. IV C5, 477-82, 1997.

[6] P. Schlosser, PhD thesis, Université de Grenoble, France, 2008.

[7] P. Schlosser, H. Louche, D. Favier, and L. Orgéas, Strain, vol. 43, 260-271, 2007.

[8] D. Favier, H. Louche, P. Schlosser, L. Orgéas, P. Vacher, and L. Debove, Acta Materialia, vol. 55, 5310-22, 2007.

[9] Y. Liu, Y. Liu, and J. Humbeeck, Scripta Mater, vol. 38, 1047-1055, 1998.

[10] P. Sittner, Y. Liu, and V. Novak, Journal of the Mechanics and Physics of Solids, vol. 53, 1719-1746, 2005.

[11] V. Grolleau, B. Galpin, A. Penin, and G. Rio, Int. J. of Crashworthiness, vol 13(4), 363-373, 2008.

[12] V. Grolleau, G. Gary, and D. Mohr, Experimental Mechanics, vol. 3, 293-306, 2008,

[13] D. Favier, Habilitation Thesis, Université de Grenoble, France, 1988.

[14] D. Favier, P. Guélin, and P. Pegon, Materials Science Forum, vols. 56-58, 559-564, 1990.

[15] P. Guélin, Journal de Mécanique, vol. 19(2), 217-247, 1980.

[16] B. Wack, J.M. Terriez and P.Guélin, Acta mechanica, vol. 50, 1-2, 9-37, 1983.

[17] P. Pegon, Habilitation Thesis, Université de Grenoble, France, 1988.

[18] L. Orgéas, D. Favier, and G. Rio, Revue Européenne des Eléments Finis, 7, 8, 111-136, 1998.

[19] G. Rio, P. Y. Manach, and D. Favier, Archives of Mechanics, 47(3), 537-556, 1995. 